JPSCR: Journal of Pharmaceutical Science and Clinical Research, 2020, 01, 61-69

DOI: $10.20961 /$ jpscr.v5i1.39269

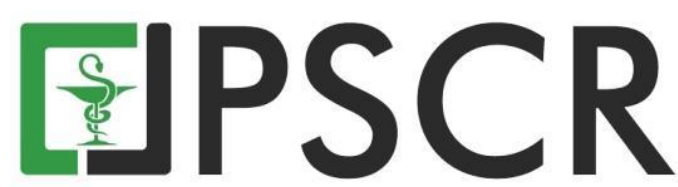

\title{
Formulasi Dan Karakterisasi Nanopartikel Ekstrak Etanol Daun Salam (Syzygium polyanthum) Pada Berbagai Variasi Komposisi Kitosan Dengan Metode Gelasi Ionik
}

\section{Dwiki Fitri, Naelaz Z. W. Kiromah* dan Tri C.Widiastuti}

Program Studi Farmasi Program Sarjana, Sekolah Tinggi Ilmu Kesehatan Muhammadiyah Gombong, Jl. Yos Sudarso No.461, Gombong, Kebumen 54412, Indonesia

*email korespondensi: naela.zukhruf18@stimugo.com

\begin{abstract}
Abstrak: Daun salam mengandung flavonoid sebagai antihipertensi, flavonoid yang diberikan secara peroral memiliki bioavailabilitas yang kurang baik karena kelarutan yang rendah dan tidak stabil terhadap faktor lingkungan. Salah satu upaya yang dapat dilakukan untuk mengatasi masalah tersebut adalah dengan memformulasikan dalam sediaan nanopartikel menggunakan polimer kitosan dan natrium tri-polifosfat (NaTPP). Penelitian ini bertujuan untuk mengkarakterisasi nanopartikel dari ekstrak etanol daun salam dengan variasi rasio konsentrasi kitosan. Ekstrak etanol daun salam diperoleh dengan cara ekstraksi menggunakan metode maserasi dengan pelarut etanol 96\%. Hasil ekstrak dibuat koloid nanopartikel menggunakan teknik gelasi ionic menggunakan variasi ekstrak etanol daun salam: kitosan: NaTPP (1:1:1); (1:5:1); dan (1:10:1). Koloid nanopartikel yang terbentuk dikarakterisasi ukuran partikel, dan nilai zeta potensial. Hasil penelitian menunjukan bahwa ekstrak etanol daun salam positif mengandung flavonoid. Hasil karakterisasi nanopartikel ekstrak etanol daun salam menunjukkan bahwa formula F1, F2, dan F3 mempunyai ukuran partikel 284,2 $\pm 6,8 ; 410,6 \pm$ 6,8; dan 630,1 $\pm 3,4 \mathrm{~nm}$ dan nilai zeta potensial F1, F2 dan F3 adalah 50,1 $\pm 4,3 ; 45,8 \pm 0,7$; dan $59,2 \pm 1,2 \mathrm{mV}$. Semua formula menunjukan rentan karakterisasi sediaan nanopartikel $(<1000 \mathrm{~nm})$ Peningkatan rasio kitosan dalam formulasi nanopartikel ekstrak etanol daun salam meningkatkan ukuran partikel dan nilai zeta potensial. F1 merupakan formula dengan ukuran partikel paling kecil dengan karakterisasi ukuran partikel $<300 \mathrm{~nm}$ dan stabilitas sistem dispersi yang optimal yaitu $>30 \mathrm{mV}$.
\end{abstract}

Kata kunci: Daun salam; nanopartikel; Kitosan; Nanoteknologi; Tautan silang

Abstract. Syzygium polyanthum leaf contains flavonoids as antihypertensive, in which it has poor bioavailability owing to its solubility and unstable during storage in ambient condition. In order to address these issues, it can be formulated in to nano particle using chitosan-sodium tripolyphosphate (NaTPP). This study purposed to characterize the Syzygium polyanthum leaf extract-formulated nanoparticles along with variation of chitosan concentration. Syzygium polyanthum leaf extract was obtained by a maceration method using $96 \%$ ethanol. Syzygium polyanthum leaf extract was prepared to nanoparticles using an ionic gelation techniquealong with ratio of extract: chitosan: NaTPP 1:1:1,1:5:1, and 1:10:1. Syzygium polyanthum extract incorporated into nanoparticle was characterized by the particle size and zeta potential. Ethanolic extract of Syzygium polyantum leaf contained flavonoids. Particle size of nanoparticle of Syzygium polyantum extract was $284.2 \pm 6.8,410.6 \pm 6.8$, and $630.1 \pm 3.4 \mathrm{~nm}$ for formula 
$\mathrm{F} 1, \mathrm{~F} 2$, and F3, respectively. In addition, zeta potential was $50.1 \pm 4.3,45.8 \pm 0.7$, and $59.2 \pm 1.2$ $\mathrm{mV}$ for $\mathrm{F} 1, \mathrm{~F} 2$, and $\mathrm{F} 3$, respectively. All formulations met the size requirements of nanoparticles in range of 10-1000 nm. All formulation fullfiled the requirement of nano particle characteristics i.e. particle size $<1000 \mathrm{~nm}$. Increasing the chitosan ratio promoted the greater particle size and zeta potential. F1 was the smallest particle size along with the most stable colloidal dispersion system.

Keywords: Syzygium polyanthum leaf; Nanoparticles; Chitosan; Nanotechnology; Crosslinking

\section{Pendahuluan}

Nanoteknologi merupakan salah satu teknologi yang melibatkan molekul dengan ukuran kurang dari 1000 nanometer (Ayumi, 2018). Applikasi nanoteknologi dalam berbagai bidang seperti kimia, biologi, fisika, dan rekayasa genetika menjadi sangat menarik dibeberapa tahun terakhir (Kurniasari \& Atun, 2017). Beberapa jenis pengembangan nanoteknologi yang sangat pesat yaitu nano-medicine, nanoemulsi dan nanopartikel. Penelitian tentang nano menjadi perhatian penting bagi peneliti dunia dikarenakan penelitian ini dapat diaplikasikan dengan sangat luas seperti dalam bidang biomedis, elektronik dan optik (Duncan \& Bevan, 2015).

Nanopartikel dapat diaplikasikan untuk menghantarkan obat dengan molekul kecil atau makromolekul besar dengan cara memerangkap atau mengenkapsulasi molekul obat kedalam suatu polimer. Polimer yang digunakan untuk membentuk nanopartikel dapat berupa polimer sintetik dan alami. Salah satu polimer yang dapat diaplikasikan dalam formulasi nanopartikel salah satunya adalah kitosan dengan agen peanut silang natrium tri-poli-fosfat (NaTPP) (Kafshgari et al, 2011). Gelasi ionik dapat dimanfaatkan untuk pembentukan nanopartikel, metode ini mempunyai kelebihan yaitu prosesnya yang sederhana atau mudah, pelarut yang digunakan bukan berasal dari pelarut organik serta prosesnya dapat dikontrol dengan mudah (Mardliyati et al, 2012).

Daun salam (Syzygium polyanthum) adalah salah jenis satu tanaman yang mempunyai manfaat untuk kesehatan salah satunya sebagai antihipertensi (Lajania, 2018). Daun salam mengandung senyawa berupa senyawa flavonoid, minyak atsiri, tannin, sitral, eugenol, seskuiterpen, triterpenoid, saponin, dan lakton (Sutanto, 2003). Kandungan senyawa flavonoid pada daun salam pada dosis tertentu efektif digunakan untuk menurunkan terjadinya hipertensi, menurunkan kadar kolesterol pada tubuh, menurunkan kadar gula dalam darah, dan menurunkan kadar asam urat (Lelono, 2009). Penelitian nanopartikel telah dilakukan oleh Natasya (2018) yang meneliti tentang karakterisasi ukuran partikel ekstrak etanol daun srikaya 
menggunakan variasi komposisi kitosan menunjukkan perbedaan pada masing-masing rasio. Hasil tersebut juga menunjukkan nilai ukuran partikel meningkat dengan peningkatan konsentrasi kitosan (Natasya, 2018). Penelitian karakterisasi pengaruh kitosan terhadap ekstrak etanol daun salam belum pernah dilaporkan.

Berdasarkan penjelasan diatas, manfaat yang ada dalam daun salam dapat ditingkatkan dengan memformulasikan menjadi bentuk nanopartikel. Penelitian ini bertujuan untuk mengkarakterisasi pengaruh variasi kitosan dan mendapatkan perbandingan ekstrak etanol daun salam: kitosan: NaTPP yang optimal menggunakan metode gelasi ionik.

\section{Bahan dan Metode}

\subsection{Bahan}

Bahan yang digunakan antara lain daun salam (Syzygium polyanthum), asam asetat glasial (Merck; Darmstadt, Jerman), kitosan (Sigma-Aldrich), etanol (Merck; Darmstadt, Jerman), Na-TPP, n-butanol, akuades, $\mathrm{FeCl}_{3}$ (Merck), $\mathrm{NaOH}$ (Merck), gelatin (Merck), reagen dragendroff, reagen lieberman burchard, lempeng silika gel GF254 (10 x 5), larutan standar kuersetin.

\subsection{Tahap pengumpulan dan penyiapan sampel}

Sampel sudah dilakukan uji determinasi tanaman di Laboratorium Biologi Universitas Ahmad Dahlan Yogyakarta, didapatkan hasil bahwa tanaman tersebut merupakan daun salam (Syzygium polyanthum). Sampel berupa daun salam (Syzygium polyanthum) diperoleh di Desa Kedungpring, Kecamatan Kemranjen, Kabupaten Banyumas, Jawa tengah Indonesia. Sampel dibersihkan dari kotoran (sortasi basah), dilakukan proses penyucucian untuk menghilangkan kotoran, dilakukan pengecilan ukuran lalu dikeringkan di tempat terbuka dengan bantuan sinar matahari. Sampel yang sudah kering dan berubah warna dilakukan sortasi kering kemudian dihaluskan sampai sampel berubah menjadi serbuk halus yang siap untuk diekstraksi.

\subsection{Ekstraksi menggunakan metode maserasi}

Serbuk daun salam (Syzygium polyanthum) dimaserasi menggunakan etanol 96\% (200 mg; 2 L) selama 24 jam dilakukan berulang sebanyak 2 kali pada suhu ruang. Ekstrak daun salam (Syzygium polyanthum) diperoleh dengan cara penyaringan menggunakan kertas saring. Ekstrak kental diperoleh dengan menguapkan ekstrak etanol menggunakan rotary evaporator.

\subsection{Deteksi kandungan aktif menggunakan uji tabung}

Deteksi kandungan aktif daun salam (Syzygium polyanthum) meliputi uji fenol, uji flavonoid, uji tannin, uji alkaloid, uji saponin dan uji steroid. 


\subsubsection{Pembuatan larutan uji}

Larutan uji dibuat dengan melarutkan sebanyak 5 g ekstrak kental etanol daun salam (Syzygium polyanthum) dengan $10 \mathrm{~mL}$ etanol 96\% (Lang, 2014).

\subsubsection{Pemerikasaan fenol}

Larutan uji diambil sebanyak $1 \mathrm{~mL}$ lalu ditetesi larutan $\mathrm{FeCl}_{3}$ lalu didiamkan beberapa saat dan lihat perubahan yang terjadi (Lang, 2014).

\subsubsection{Pemerikasaan flavonoid}

Larutan uji diambil sebanyak $1 \mathrm{~mL}$ lalu ditetesi larutan $\mathrm{NaOH}$ lalu didiamkan beberapa saat dan lihat perubahan yang terjadi (Lang, 2014).

\subsubsection{Pemeriksaan tanin}

Larutan uji diambil sebanyak $1 \mathrm{~mL}$ lalu ditetesi larutan Gelatin lalu didiamkan beberapa saat dan lihat perubahan yang terjadi (Lang, 2014).

\subsubsection{Pemeriksaan alkaloid}

Larutan uji diambil sebanyak $1 \mathrm{~mL}$ lalu ditetesi larutan dragendroff lalu didiamkan beberapa saat dan lihat perubahan yang terjadi (Lang, 2014).

\subsubsection{Pemeriksaan saponin}

Larutan uji diambil sebanyak $1 \mathrm{~mL}$ lalu lalu dikocok kuat kemudian didiamkan beberapa saat (Lang, 2014).

\subsubsection{Pemeriksaan steroid}

Larutan uji diambil sebanyak $1 \mathrm{~mL}$ lalu ditetesi larutan Pereaksi Lieberman Burchard lalu didiamkan beberapa saat dan lihat perubahan yang terjadi (Nofiandi, 2017).

\subsection{Identifikasi senyawa menggunakan kromatografi lapis tipis (KLT)}

Identifikasi senyawa menggunakan KLT untuk mengetahui lebih pasti adanya senyawa flavonoid dimana senyawa ini yang digunakan untuk menurunkan tekanan darah. Identifikasi menggunakan KLT (Kromatografi Lapis Tipis) menggunakan pelarut n-butanol; air; asam asetat dengan perbandingan 4:5:1 menggunakan plat silica gel GF 254 lalu diamati menggunakan lampu UV pada panjang gelombang 254 dan $366 \mathrm{~nm}$.

\subsection{Pembuatan nanopartikel ekstrak etanol daun salam (Syzygium polyanthum)}

Sebanyak 1 g ekstrak kental dari daun salam (Syzygium polyanthum) ditimbang dan dilarutkan ke dalam $35 \mathrm{~mL}$ etanol, kemudian ditambahkan $15 \mathrm{~mL}$ akuades. Kitosan dengan berbagai variasi bobot dilarutkan ke dalam $100 \mathrm{~mL}$ asam asetat glasial 1\%. Variasi komposisi perbandingan ekstrak, kitosan, dan NaTPP pada larutan yaitu pada perbandingan $(1: 1: 1)$, 
(1:5:1), dan (1:10:1). Setelah bahan tercampur dilanjutkan pengadukan menggunakan magnetic stirrer selama 2 jam. Ukuran partikel dan zeta potensial diukur menggunakan Malvern particle size analyzer (UK).

\section{Hasil dan Pembahasan}

Ekstraksi daun salam (Syzygium polyanthum) sebanyak $800 \mathrm{~g}$ menggunakan pelarut etanol 96\% didapatkan 102,136 g ekstrak kental dengam rendemen 12,77\%. Karakterisasi kandungan metabolit yang terdapat pada ekstrak daun salam perlu dilakukan identifikasi untuk menentukan aspek preformulasi dalam formulasi nanopartikel ekstrak etanol daun salam. Deteksi kandungan aktif daun salam (Syzigium polyanthum) meliputi uji fenol, uji flavonoid, uji tannin, uji alkaloid, uji saponin dan uji steroid. Hasil deteksi kandungan aktif menggunakan uji tabung dilihat pada Tabel 1. Hasilnya menunjukan bahwa ekstrak etanol daun salam mengandung senyawa fenol, flavonoid, tannin dan steroid.

Tabel 1. Hasil deteksi kandungan aktif ekstrak etanol daun salam menggunakan pereaksi warna menggunakan uji tabung.

\begin{tabular}{llll}
\hline Skrining & Pereaksi & Hasil & Keterangan \\
\hline Fenol & $\mathrm{FeCl}_{3}$ & Hijau & Positif \\
Flavonoid & $\mathrm{NaOH}$ & Kuning & Positif \\
Tanin & Gelatin & Ada endapan & Positif \\
Alkaloid & Dragendroff & Tidak ada noda jingga & Negatif \\
Saponin & Kocok kuat & Tidak timbul busa & Negatif \\
Steroid & Liebermann Burchard & Coklat Positif & Positif \\
\hline
\end{tabular}

Hasil analisa secara kualitatif menggunakan KLT dilihat pada Gambar 1. Plat KLT (Gambar 1a) merupakan hasil uji KLT ekstrak etanol daun salam yang diamati pada panjang gelombang 254nm sedangkan pada Gambar 1b. merupakan hasil uji KLT ekstrak etanol daun salam yang diamati dengan panjang gelombang $366 \mathrm{~nm}$.

Hasil yang diperoleh yaitu nilai Rf ekstrak etanol daun salam (Syzygium polyanthum) yang didapatkan sama dengan nilai Rf larutan pembanding kuarsetin yaitu 0,925. Peredaman noda pada panjang gelombang $366 \mathrm{~nm}$, kuarsetin menunjukan noda berwarna kuning, sedangkan pada ekstrak menunjukan noda warna hitam (tidak redam sinar UV $366 \mathrm{~nm}$ ). Hal tersebut dapat disimpulkan bahwa komponen flavonoid kuarsetin tidak dominan ekstrak etanol daun salam. Dimungkinkan komponen dominan adalah kelompok fenolik.

Penelitian ini menggunakan variasi konsentrasi kombinasi polimer kitosan dan tri-polifosfat. Pencampuran polimer tersebut akan menghasilkan interaksi antara polimer yang bermuatan positif pada gugus amino kitosan dengan polimer yang bermuatan negatif dari tri- 
poli-fosfat. Konsentrasi antara polimer kitosan dan tri-poli-fosfat yang digunakan dapat mempengaruhi katrakteristik fisik dari nanopartikel (Rismana, 2014). Penggunaan kitosan pada penelitian ini disebabkan karena kitosan yang memiliki sifat antibakteri, biokompatibel, pengelat dan bioaktif, serta dapat terbiodegrasi. Selain itu kitosan sangat cepat menyerap air dan memiliki derajat swelling yang tinggi dalam lingkungan air, oleh sehingga pada aplikasi medis dan aplikasi biologis sebagai sistem penghantaran dan pelepasan obat kurang menguntungkan. Sehingga penambahan NaTPP perlu dilakukan untuk menghasilkan turunan kitosan dengan peningkatan biokompatibilitas swelling dan menurunkan derajat swellimg yang sangat tinggi (Ermina et al, 2016).

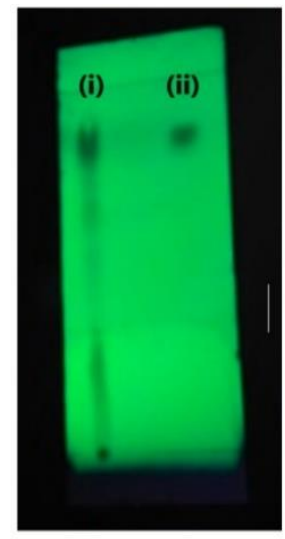

a

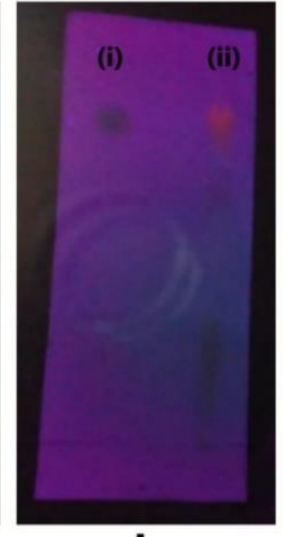

b

Gambar 1. Visualisasi plat kromatografi lapis tipis ekstrak etanol daun salam pada panjang gelombang $254 \mathrm{~nm}$ (a) dan $366 \mathrm{~nm}$ (b). Ekstrak etanol daun salam (i) dan kuarsetin (ii).

Teknik gelasi ionik memanfaatkan NaTPP yang digunakan sebagai agen crosslinker dengan konsentrasi rendah dilakukan supaya tidak terbentuk ikantan tautan silang antara polianion pada TPP dengan gugus amino pada polikation kitosan. Counter charge tersebut akan berinteraksi dan menyebabkan rantai polimer kitosan menggulung (Abdassah, 2009). Senyawasenyawa polifenol dalam ekstrak akan berikatan dengan gugus kation pada kitosan, sedangkan sisa kation akan bereaksi dengan NaTPP sehingga menyebabkan rantai molekul kitosan membentuk partikel-partikel berbentuk nano. Metode ini merupakan metode yang paling mudah dilakukan jika dibandingkan dengan metode-metode yang lainnya (Mohanraj, 2006). Kitosan yang terprotonasi pada asam kemudian ditambahkan dengan counter charge, secara spontan akan terbentuk nanopartikel. Ukuran dan struktur permukaan pada partikel dapat dimodifikasi dengan memvariasikan rasio atau komposisi kitosan dan NaTPP (Kurniasari \& Atun, 2017). Rizal (2018) melaporkan bahwa perubahan ukuran partikel dari nanopartikel ekstrak etanol 
daun nangka (Artocarpus heterophyllus lam.) yaitu 1:1 (382,6 nm), 2:1 (199,2 nm), dan 3:1 (402,2 nm) menunjukkan hubungan parabolic dengan perubahan variasi komposisi kitosannatrium tripolifosfat. Hasil ini memperkuat bahwa adanya perbedaan yang signifikan terkait ukuran pada setiap variasi atau formula.

Pada penelitian ini mengaplikasikan variasi rasio konsentrasi kombinasi polimer kitosan dan tri-poli-fosfat pada perbandingan yang digunakan adalah perbandingan ekstrak etanol daun salam (Syzygium polyanthum): kitosan: NaTPP formula I 1:1:1, formula 2 1:5:1 dan formula 3 1:10:1 (Gambar 2). Hasil menunjukan bahwa F1 memiliki warna keruh, sedangkan F2 lebih jernih dan F3 paling jernih. Meningkatnya rasio kitosan dalam sistem meningkatkan kejernihan dari dispersi yang terbentuk.

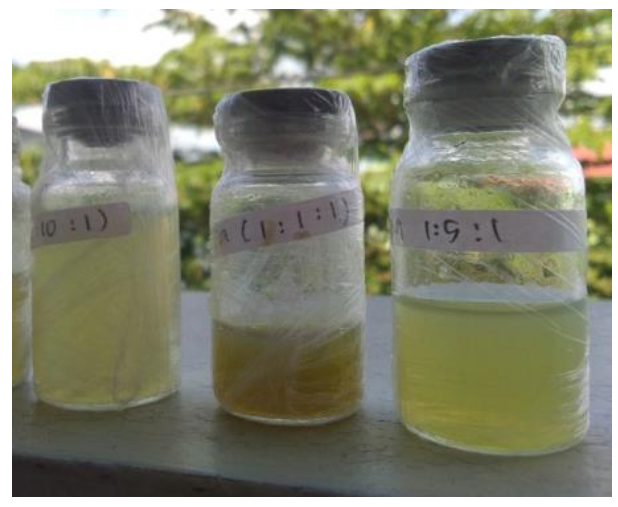

Gambar 2. Hasil fisik larutan nanopartikel dengan masing-masing perbandingan ekstrak etanol daun salam (Syzygium polyanthum): kitosan: NaTPP secara berurutan yaitu kiri (1:10:1), tengah $(1: 1: 1)$ dan kanan $(1: 5: 1)$.

Adanya variasi komposisi kitosan tersebut berpengaruh pada ukuran partikel dan nilai zeta potensial pada masing-masing variasi (Gambar 3). Peningkatan rasio kitosan dalam sistem meningkatkan ukuran partikel dari nanopartikel ekstrak daun salam. Jumlah kitosan yang berlebih kemudian dikompleks melalui tautan silang dengan counter ion, natrium tri-poli-fosfat (NaTPP), jumlah kitosan akan meningkatkan ukuran partikel karena struktur folding rantai polimer yang terdispersi semakin besar dan semakin banyak. Nilai zeta potensial yang positif disebabkan karena kontribusi dari muatan parsial pada permukaan yang didominasi oleh kitosan (bermuatan positif) sehingga beda potensial antara electrical double layer dan medium bernilai positif. Nilai zeta potensial yang >30 menunjukkan repulsion force lebih besar dari pada attractive force sehingga mampu meningkatkan stabilitas sistem dispersi. 


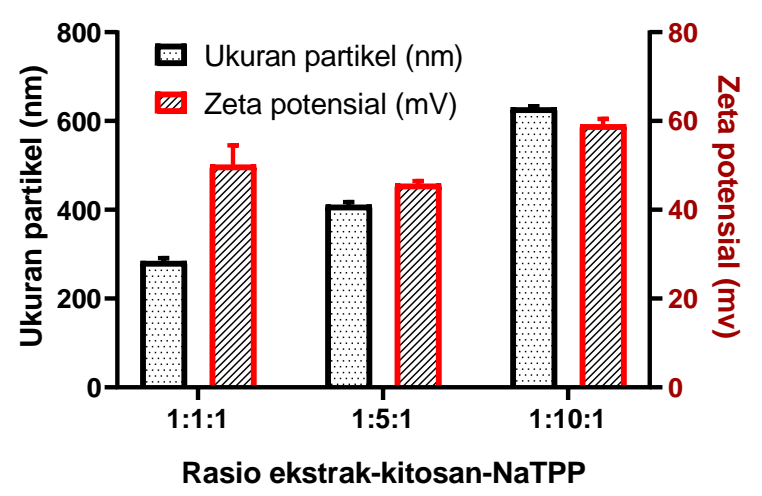

Gambar 3. Ukuran partikel dan zeta potensial dari nanopartikel ekstrak etanol daun salam dengan variasi rasio ekstrak-kitosan-natrium tripolifosfat (NaTPP).

\section{Kesimpulan}

Hasil penelitian menunjukan bahwa ekstrak etanol daun salam positif mengandung senyawa flavonoid. Hasil karakterisasi nanopartikel ekstrak etanol daun salam menunjukkan F1, F2, dan F3 memiliki rata-rata ukuran partikel yaitu 284,2 $\pm 6,8 ; 410,6 \pm 6,8$; dan 630,1 \pm $3,4 \mathrm{~nm}$ dan nilai zeta potensial F1, F2 dan F3 adalah 50,1 $\pm 4,3 ; 45,8 \pm 0,7$; dan 59,2 $\pm 1,2 \mathrm{mV}$. F1 merupakan formula dengan ukuran partikel paling kecil dengan karakterisasi ukuran partikel $<300 \mathrm{~nm}$ dan stabilitas sistem dispersi yang optimal yaitu $>30 \mathrm{mV}$. Analisis hasil pembuatan nanopartikel lebih baik jika di lanjutkan untuk uji SEM untuk melihat hasil dari bentuk nanopartikel tersebut.

\section{Ucapan Terimakasih}

Penelitian ini didanai oleh Program Kreativitas Mahasiswa (PKM) Kemenristekdikti tahun 2019 dengan nomor kontrak 063051C11600002. Terimakasih disampaikan kepada Agung Setiawan dan Astri Ayu Febriyuliani terkait bantuan teknis di laboratorium.

\section{Deklarasi Konflik Kepentingan}

Semua penulis (Dwiki Fitri, Naelaz Zukhruf Wakhidatul Kiromah, Tri Cahyani Widiastuti) menyatakan tidak ada konflik kepentingan apapun terhadap penulisan naskah ini.

\section{Daftar Pustaka}

Abdassah M. (2009). Nanopartikel Dengan Gelasi Ionik. Farmaka,15(1), pp:45-52.

Ayumi, D., Sumaiyah, S., \& Masfria, M. (2018). Pembuatan Dan Karaterisasi Nanopartikel Ekstrak Etanol Daun Ekor Naga (Rhaphidophora pinnata (L.f.) Schott) Menggunakan Metode Gelasi Ionik. Talenta Conference Series: Tropical Medicine (TM), 1(3), 029033.

Duncan, G. A., \& Bevan, M. A. (2015). Computational Design of Nanoparticle Drug Delivery Systems for Selective Targeting. Nanoscale, $7: 15332-15340$.

Ermina Pakki, Sumarheni, Aisyah F, Ismail, S. S. (2016). Formulasi Nanopartikel Ekstrak 
Bawang Dayak (Eleutherine Americana (Aubl) Merr) Dengan Variasi Konsentrasi Kitosan- Tripolifosfat (Tpp). Journal of Tropical Pharmacy and Chemistry, 3(4), 251263.

Kafshgari, M. H., Khorram, M., Khodadoost, M., \& Khavari, S. (2011). Reinforcement of Chitosan Nanoparticles Obtained by an Ionic Cross-linking Process. IrANIAN Polymer Journal, 20(5), 445-456.

Kurniasari, D., \& Atun, S. (2017). Pembuatan Dan Karakterisasi Nanopartikel Ekstrak Etanol Temu Kunci ( Boesenbergia Pandurata ) Pada Berbagai Variasi Komposisi Alginat. Jurnal Kimia Dasar, 6(1), 31-35.

Lajania, H. S., Effendi, E. M., Indriani, L., \& Siam, S. L. (2018). Efektivitas Kombinasi Ekstrak Daun Salam (Syzygium polyanthum) Dan Sari Labu Siam (Sechium edule (Jacq.) Sw.) Sebagai Antihipertensi Pada Tikus Jantan. Jurnal Online Mahasiswa (JOM) Bidang Farmasi, 1(1)

Lelono, R. A. A., Tachibaba. S \& Itoh, K. (2009). in vitro antioxidative activities and polyphenol content of eugenia polyantha wight grown in indonesia. Pakistan Journal of Biological Sciences, 12 (24) : 1564-1570.

Mardliyati, E., El, S., \& Ria, D. (2012). Sintesis Nanopartikel Kitosan- Trypoly Phosphate Dengan Metode Gelasi Ionik: Pengaruh Konsentrasi Dan Rasio Volume Terhadap Karakteristik Partikel.Prosiding Pertemuan Ilmiah Ilmur Pengetahuan dan Teknologi Bahan, 90: 93.

Mohanraj, V.J. and Chen, Y. (2006). Nanoparticles - A Review.Tropical Journal of Pharmaceutical Research, 5(1), pp:561-73.

Natasya B. (2018). Pembuatan Nanopartikel dari Ekstrak Etanol Daun Srikaya ( Annona Squamosa L .) dan Uji Aktivitas Antibakteri Terhadap Staphylococcus aureus dan Escherichia coli. Repositori Institusi Universitas Sumatera Utara, Fak Farm http//repositori.usu.ac.id.

Nofiandi. (2017). Kadar Fenolat Total Dan Aktivitas Antioksidan Daun Salam ( Syzygium polyanthum ( Wight ) Walp .). STIFI Perintis Padang, 2(2), 53-60.

Rizal Siyam Triatmojo. (2018). Pembuatan Dan Karakterisasi Nanopartikel Ekstrak Etanol Daun Nangka (Artocarpus Heterophyllus Lam.) Pada Berbagai Variasi Komposisi Kitosan-Natrium Tripolifosfat. Disertasi, Universitas Wahid Hasyim Semarang.

Rismana, E. Kusumaningrum, S. dan Bunga, O. (2014). Pengujian Aktivitas Antiacne Nanopartikel Kitosan - Ekstrak Kulit Buah Manggis (Garcinia Mangostana ). Media Penelitian dan Pengembangan Kesehatan, 24(1), pp:19-27.

Sutanto T. (2003) Asam Urat deteksi, pencegahan, pengobatan. Yogyakarta: Penerbit Buku Pintar.

Lang, T. (2014). Standarisasi dan Profil Kromatogram Ekstrak Air dan Ekstrak Etanol Daun Salam (Syzygium polyanthum). Disertasi, Widya Mandala Catholic University

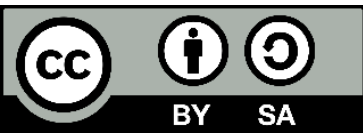

2020 by the authors. Submitted for possible open access publication under the terms and conditions of the Creative Commons Attribution-ShareAlike 4.0 International (CC BY-SA 4.0) license (https://creativecommons.org/licenses/by-sa/4.0/). 